\title{
Trade, Growth, and Technology Equalization
}

by

\author{
John J. Seater \\ Economics Department \\ North Carolina State University \\ Raleigh, NC 27695-8910 \\ john_seater@ncsu.edu
}




\begin{abstract}
Trade is shown to increase economic growth purely through comparative advantage without recourse to scale effects, technology transfer, research and development, or even international investment. The resulting growth rates are those that would result from technology transfer, even though no technology transfer actually occurs. A balanced growth rate exists, is identical for all countries and therefore the world, and is asymptotically stable if and only if each country has an absolute (not just comparative) advantage in something. When balanced growth does not exist, trade reduces but does not eliminate differences between countries' growth rates. Trade therefore does not necessarily guarantee a stable world income distribution. The magnitude of trade's effect on growth depends on the goods imported, not those exported.
\end{abstract}

Keywords: trade, growth, technology equalization, comparative advantage, absolute advantage, world income distribution

JEL classification codes: O4, F15 


\section{Introduction}

A long-standing issue in the endogenous growth literature is the effect of international trade on growth rates. Does trade promote economic growth? How? It is tempting to presume that trade raises growth rates in a dynamic model in the same way that it raises the level of income in a static model - by allowing countries to exploit their comparative advantages in production. To date, however, that presumption has not been established theoretically. The existing literature examines other channels through which trade may affect growth, such as an improved climate for research and development, but there is no demonstration that pure comparative advantage affects economic growth. The present paper provides such a demonstration.

In the existing literature, trade affects growth in three ways - through scale effects, technology transfer, and increased global efficiency in research and development. In models that have scale effects, opening a country to trade in effect increases its size, which then leads to a higher growth rate through the scale effect. For example, Kremer (1990) argues that trade increases the relevant population size and thereby raises the rate of technical progress; Barro and Sala-i-Martin (1997) and Connolly (2000) present models in which trade expands markets and so raises profitability of producing intermediate goods, leading to more production of those goods and consequently higher growth. In models of technology transfer, trade is a vehicle for the exchange of technological knowhow. Trade opens countries to each other's knowledge, allowing each country to learn and adopt the production techniques of its trading partners, and so increasing its stock of knowledge. Because the rate of knowledge accumulation is treated as proportional to the stock of existing knowledge, the technology transfer enabled by trade raises the growth rates of all trading partners. Rivera-Batiz and 
Romer (1991) discuss two such models. They explicitly point out that the growth effects of trade in their models arise from scale effects and not from comparative advantage. More recently, Howitt (2000) has used a technology-transfer model of Schumpeterian growth to study cross-country income differences; in the model, countries that are relatively good at research and development share technology with each other and grow fast compared to countries that are not good at R\&D and that end up not being included in the technology sharing. Acemoglu and Ventura (2002) also study the world income distribution, using a model in which countries are endowed with the ability to produce different sets of intermediate goods. Opening the countries to trade makes the different goods available to everyone and so leads to higher growth through an increased variety of intermediates. All these models have two characteristics that are important for our discussion here: the increase in growth ultimately reflects a kind of scale effect (the instantaneous jump in the stock of knowledge), and comparative advantage plays no role. In models where growth arises from research and development, comparative advantage plays a tangential role in fostering growth. In Grossman and Helpman's (1990, 1991, 1995) work, for example, some countries have a comparative advantage in research and development. Trade allows those countries to specialize in what they are relatively good at - doing R\&D - and so making all countries grow faster. In these models, though, the growth effects of trade are driven by research and development, not comparative advantage. If there were no increase in research and development, there also would be no increase in any country's growth rate. A similar conclusion holds for Young's (1991) interesting model, in which trade alters growth by changing 
countries' patterns of learning-by-doing. ${ }^{1}$

The evidence on whether trade causes growth is not decisive, but it tends to support a statistically and economically significant effect. Models in which trade works through the scale effect receive mixed support; see, for example, Backus, Kehoe, and Kehoe (1992). The evidence is more supportive of the possibility that trade affects growth through the research and development and the technology transfer channels. The classic citation, perhaps, is Coe and Helpman (1995), who provide evidence that $R \& D$ in one country improves growth in a trading partner. The interesting thing for our purposes here, however, is that there also is evidence that trade may affect growth directly rather than through R\&D or technology transfer. Alcala and Ciccone (2001), for example, find strong and robust effects of trade on growth. Their measure of openness to trade does not depend on in any way on technology transfer or R\&D; it is based on a general measure of the volume of trade. Their results suggest the possibility that trade in and of itself boosts growth. What is missing, though, is a theoretical argument showing why trade should affect growth. The present paper addresses that issue and shows that trade raises growth through the same comparative advantage mechanism that raises the income level in static models without growth.

${ }^{1}$ One contribution that stands apart from all others is Ventura's (1997) discussion of how trade, through comparative advantage, distributes growth among countries. Although Ventura's discussion concerns trade and growth, it is unrelated to the issues we examine below. The issues addressed are quite different. Ventura addresses the issue of how to use cross-country data to tests implications of growth theory; the analysis below examines the effect of trade on the balanced growth rates of both individual countries and the world as a whole. Indeed, in Ventura's analysis, trade has no effect on the world's balanced growth rate (see his equation 11), whereas in the endogenous growth model used below, trade raises the growth rates of all trading countries and increases the world's rate of growth along the balanced growth path. 
The model we study has no scale effects, no research and development, no technology transfer, and no international investment, so any effects of trade and growth cannot reflect those influences. The model has two countries producing two goods, each good being produced in its own sector. One good is purely a capital good; the other can be used either as a second type of capital or as consumption. The trade aspects of the model are Ricardian: countries differ in their technologies, and there are no fixed factors. Comparative advantage guarantees trade, but an interesting result is that important aspects of trade's effect on growth depend on the absolute advantages of the trading countries. In particular, equilibrium with trade can be an interior solution or a corner solution. An interior solution occurs if and only if each country has an absolute advantage in the production of a good. When that condition is met, trade leads to an increase in both countries' growth rates and replicates the result that would emerge if countries exchanged technology, even though no technology transfer actually takes place. A corner solution occurs if one country (the "disadvantaged country") has no absolute advantage in any good. In that case, trade can raise the disadvantaged country's growth rate but always leaves it below the growth rate of the other country, whose growth rate is unaffected by trade. Trade therefore need not guarantee a stable world income distribution, contrary to the conclusion obtained by Acemoglu and Ventura (2002).

We thus are led to a technology equalization theorem, related in its structure to the HecksherOhlin-Samuelson theorem on factor price equalization. The theorem roughly says that trade in goods substitutes for technology transfer - the growth rates of countries with different technologies are the same in the presence of trade as they would have been had those countries agreed to share technological knowledge, except for the corner solution case, where trade leads to no more than partial 
technology equalization. The theorem also provides conditions for existence and asymptotic stability of the balanced growth rate.

The model leading to the theorem thus offers a possible explanation of why some countries persistently have lower growth rates than others. It also has implications for trade policy and its effects. Government policies that create an absolute advantage in something can increase a country's growth rate. However, the analysis shows that trade's effect on growth depends on the kind of good that is imported, not the kind that is exported. Increasing the growth rate through trade requires importing factors of production. Government policies attempting to create absolute advantage in an industry must be aimed at goods that can be exchanged in the world market for factors of production, not only for consumption goods.

\section{The Model Under Autarky}

We start with case of autarky to keep the model simple and allow us to understand its structure. In subsequent sections, we introduce trade and study its effects on growth. The autarkic model is that discussed by Barro and Sala-I-Martin (1995, chapter 5), so we can proceed fairly quickly in summarizing it here. ${ }^{2}$

Two goods $\mathrm{Y}$ and $\mathrm{H}$ are produced in the economy. The $\mathrm{Y}$ good can be used for consumption $\mathrm{C}$ or can be used as gross investment $\mathrm{I}$ in one kind of capital $\mathrm{K}$. The $\mathrm{H}$ good is another type of capital and is produced in a different sector from the Y good by a different technology. Each sector's

\footnotetext{
${ }^{2}$ Mathematical details are in an Appendix available from the author.
} 
technology is Cobb-Douglas. Each type of capital depreciates at the rate $\delta$. Thus we have

$$
\begin{aligned}
& Y_{t}=C_{t}+I_{t} \\
& =A\left(v_{t} K_{t}\right)^{\star}\left(u_{t} H_{t}\right)^{1-s} \\
& \dot{H}_{t}+\delta H_{t}=B\left[\left(1-v_{t}\right) K_{t}\right]^{n}\left[\left(1-u_{t}\right) H_{t}\right]^{1-\eta}
\end{aligned}
$$

where $\mathrm{v}$ and $\mathrm{u}$ are the fractions of total $\mathrm{K}$ and $\mathrm{H}$ that are used in the $\mathrm{Y}$-producing sector.

Utility is CRRA, so lifetime utility is:

$$
U=\int_{0}^{-C_{t}^{1-\theta}-1} \frac{1}{1-\theta} e^{p t} d t
$$

The representative agent maximizes his lifetime utility subject to (1), (2), and the usual initial and terminal conditions. The Hamiltonian is

$$
\begin{gathered}
V=\frac{C_{t}^{1-\theta}-1}{1-\theta} e^{-p t}+\phi_{t}\left[A\left(v_{t} K_{t}\right)^{s}\left(u_{t} H_{t}\right)^{1-\Sigma}-8 K_{t}-C_{t}\right] \\
+\Psi_{t}\left\{B\left[\left(1-v_{t}\right) K_{t}\right]^{\eta}\left[\left(1-u_{t}\right) H_{t}\right]^{1-\eta}-8 H_{t}\right\}
\end{gathered}
$$

and the necessary conditions include (1), (2), and ${ }^{3}$

$$
\begin{aligned}
\dot{\phi}_{t}=-\frac{\partial V}{\partial K}=- & \phi_{t}\left[\alpha v_{t} A\left(v_{t} K_{t}\right)^{\varepsilon-1}\left(u_{t} H_{t}\right)^{1-\star}-8\right] \\
& -\Psi_{t}\left\{\eta\left(1-v_{t}\right) B\left[\left(1-v_{t}\right) K_{t}\right]^{n-1}\left[\left(1-u_{t}\right) H_{t}\right]^{1-\eta}\right\}
\end{aligned}
$$

${ }^{3}$ The necessary conditions also include the initial and transversality conditions, which are suppressed here and in the sequel for brevity. 
(6)

$$
\begin{aligned}
\dot{\psi}_{t}=-\frac{\partial V}{\partial H}=-\phi_{t} & {\left[(1-\alpha) u_{t} A\left(v_{t} K_{t}\right)^{*}\left(u_{t} H_{t}\right)^{-*}\right] } \\
& -\psi_{t}\left\{(1-\eta)\left(1-u_{t}\right) B\left[\left(1-v_{t}\right) K_{t}\right]^{n}\left[\left(1-u_{t}\right) H_{t}\right]^{\eta}-8\right\}
\end{aligned}
$$

$$
\frac{\partial V}{\partial C}=0=C_{t}^{-\theta} e^{-\rho t}-\phi_{t}
$$

$$
\begin{array}{rl}
\frac{\partial V}{\partial v}=0=\phi_{t} \Delta K_{t} & A\left(v_{t} K_{t}\right)^{a-1}\left(u_{t} H_{t}\right)^{1-\alpha} \\
& -\Psi_{t} \eta K_{t} B\left[\left(1-v_{t}\right) K_{t}\right]^{\eta}\left[\left(1-u_{t}\right) H_{t}\right]^{-\eta}
\end{array}
$$

$$
\begin{aligned}
\frac{\partial V}{\partial u}=0=\phi_{t}(1-x) H_{t} A\left(v_{t} K_{t}\right)^{a}\left(u_{t} H_{t}\right)^{-\varepsilon} \\
\quad-\Psi_{t}(1-\eta) H_{t} B\left[\left(1-v_{t}\right) K_{t}\right]^{n}\left[\left(1-u_{t}\right) H_{t}\right]^{\eta}
\end{aligned}
$$

Henceforth, time subscripts will be omitted except when clarity demands otherwise.

Differentiating (7) with respect to time, rearranging, and using (5) and (8), gives the growth rate

$\gamma_{\mathrm{C}}$ for consumption:

$$
Y_{c}=\frac{1}{\theta}\left[\alpha A\left(\frac{v K}{u H}\right)^{-(1-\infty)}-\delta-p\right]
$$

Using (8) and (9), we can obtain the relation

$$
\left(\frac{\eta}{1-\eta}\right)\left(\frac{v}{1-v}\right)=\left(\frac{x}{1-\alpha}\right)\left(\frac{u}{1-u}\right)
$$

Competitive equilibrium requires that the rate of return on $\mathrm{K}$ be the same in the two sectors of production, and similarly for the rate of return on $\mathrm{H}$ : 


$$
\begin{aligned}
\frac{\partial Y}{\partial(v K)} & =p \frac{\partial(\dot{H}+\delta H)}{\partial[(1-v) K]} \\
-\quad \alpha A\left(\frac{v K}{u H}\right)^{u-1} & =p \eta B\left[\frac{(1-v) K}{(1-u) H}\right]^{\eta-1} \\
\frac{\partial Y}{\partial(u H)} & =p \frac{\partial(\dot{H}+\delta H)}{\partial[(1-u) H]} \\
-\quad(1-\alpha) A\left(\frac{v K}{u H}\right)^{*} & =p(1-\eta) B\left[\frac{(1-v) K}{(1-u) H}\right]^{\eta}
\end{aligned}
$$

where $\mathrm{p}$ is the price of $\mathrm{H}$ in terms of $\mathrm{Y}$. We obtain $\mathrm{p}$ from (11) and either (12) or (13):

$$
p=\left(\frac{A}{B}\right)\left(\frac{\alpha}{\eta}\right)^{\eta}\left(\frac{1-\alpha}{1-\eta}\right)^{1-\eta}\left(\frac{v K}{u H}\right)^{\alpha-\eta}
$$

We now can define gross domestic product:

$$
Q=P+p(\dot{H}+\delta H)
$$

We want to obtain the balanced growth solution for this economy. Balanced growth requires that all variables grow at constant rates (which may be zero for some variables). We begin with the growth rate of $\mathrm{p}$. We can write $\mathrm{p}$ in two ways. Equation (14) is one; the other is obtained by noting that the costate variables $\phi$ and $\psi$ are, respectively, the marginal value of Y-goods and of H-goods in terms of utility. Consequently, their ratio is the marginal value of $\mathrm{H}$-goods in terms of Y-goods, which is p:

$$
p=\frac{\psi}{\phi}
$$

which implies immediately that 


$$
\gamma_{p}=\frac{\dot{p}}{p}=\frac{\dot{\psi}}{\psi}-\frac{\dot{\phi}}{\phi}
$$

We then can use (5), (6), and (11) to obtain (after much manipulation) one expression for $\gamma_{\mathrm{p}}$ :

$$
\gamma_{p}=(\alpha-\eta)\left(\gamma_{Z}+\gamma_{I}-\gamma_{B}\right)
$$

where $\mathrm{Z} \equiv \mathrm{v} / \mathrm{u} .{ }^{4}$ The other equation for $\gamma_{\mathrm{p}}$ is obtained from (14):

$$
Y_{p}=A\left\{\alpha\left(Z \frac{K}{H}\right)^{s-1}-(1-\alpha)\left[\left(\frac{A}{B}\right)\left(\frac{\alpha}{\eta}\right)^{\eta}\left(\frac{1-\alpha}{1-\eta}\right)\right]^{-1}\left(Z \frac{K}{H}\right)^{\eta}\right\}
$$

Equating these two expression for $\gamma_{\mathrm{p}}$ gives

$$
\gamma_{Z}+\gamma_{I}-\gamma_{B}=\frac{A}{\alpha-\eta}\left\{\alpha\left(Z \frac{K}{H}\right)^{\alpha-1}-(1-\alpha)\left[\left(\frac{A}{B}\right)\left(\frac{\alpha}{\eta}\right)^{\eta}\left(\frac{1-\alpha}{1-\eta}\right)\right]^{-1}\left(Z \frac{K}{H}\right)^{\eta}\right\}
$$

We obtain the growth rates of $\mathrm{K}, \mathrm{H}$, and $\mathrm{C}$ from (10), (5), and (6):

$$
\begin{aligned}
& \gamma_{\boldsymbol{X}}=A\left(Z \frac{K}{H}\right)^{\alpha-1}-\frac{C}{K}-\delta \\
& \gamma_{B}=B\left(\frac{\eta}{1-\eta}\right)^{\eta}\left(\frac{1-\alpha}{\alpha}\right)^{\eta}\left(Z \frac{K}{H}\right)^{\alpha-1}-\delta \\
& \gamma_{C}=\frac{1}{\theta}\left[\alpha A\left(Z \frac{K}{H}\right)^{(\alpha-1)}-\delta-\rho\right]
\end{aligned}
$$

We can use these four equations and the definition of $Z$ to establish the following characteristics of the

${ }^{4} \mathrm{We}$ can write $\mathrm{Z}$ as

$$
Z=\frac{\alpha(1-\eta)}{(1-\alpha) \eta+(\alpha-\eta) u}
$$

by solving (11) for $v$ in terms of $u$ and substituting. This transformation is used in deriving some of the results that follow. 
balanced growth path:

(I) The growth rates of $\mathrm{C}, \mathrm{K}, \mathrm{Y}, \mathrm{H}$, and $\mathrm{Q}$ are equal

$$
\gamma=\gamma_{C}=\gamma_{Z}=\gamma_{P}=\gamma_{B}=\gamma_{D}
$$

(ii) The ratios $\mathrm{C} / \mathrm{K}$ and $\mathrm{K} / \mathrm{H}$ therefore are constant.

(iii) The growth rates of $\mathrm{p}, \mathrm{u}, \mathrm{v}$, and $\mathrm{Z}$ are zero

$$
\gamma_{p}=\gamma_{u}=\gamma_{v}=\gamma_{z}=0
$$

(iv) The value of $\mathrm{Z}(\mathrm{K} / \mathrm{H})$ is

$$
Z \frac{K}{H}=\left(\frac{A}{B}\right)^{\frac{1}{1-\alpha+\eta}}\left(\frac{x}{1-\alpha}\right)^{\frac{1}{1-\alpha+\eta}}\left(\frac{x}{\eta}\right)^{\frac{1}{1-\alpha+\eta}}\left(\frac{1-\alpha}{1-\eta}\right)^{\frac{1}{1-\alpha+\eta}}
$$

(v) The value of $\gamma$ is

$$
\gamma=\frac{1}{\theta}\left[A^{\frac{\eta}{1-\varepsilon+\eta}} B^{\frac{1-\varepsilon}{1-\alpha+\eta}} \alpha^{\frac{\varepsilon \eta}{1-\alpha+\eta}}(1-\alpha)^{\frac{(1-\alpha) \eta}{1-\alpha+\eta}} \eta^{\frac{(1-\varepsilon) \eta}{1-\alpha+\eta}}(1-\eta)^{\frac{(1-\varepsilon)(1-\eta)}{1-\alpha+\eta}}-\delta-\rho\right]
$$

(vi) The value of $p$ is

$$
p=\left(\frac{A}{B}\right)\left(\frac{\alpha}{\eta}\right)^{\eta}\left(\frac{1-\alpha}{1-\eta}\right)^{1-\eta}\left[\left(\frac{A}{B}\right)^{\frac{1}{1-\alpha+\eta}}\left(\frac{\alpha}{1-\alpha}\right)^{\frac{1}{1-\alpha+\eta}}\left(\frac{\alpha}{\eta}\right)^{\frac{1}{1-\alpha+\eta}}\left(\frac{1-\alpha}{1-\eta}\right)^{\frac{1}{1-\alpha+\eta}}\right]^{s-\eta}
$$

\section{Fundamentals of Trade and Growth}

We now want to introduce foreign trade into the model. We begin with some simple cases that make the intuition clear and examine generalizations later. We presume a Ricardian model of trade with 
no fixed factors but with countries possibly having different technologies. ${ }^{5}$ In our framework of a twofactor Cobb-Douglas production function, technology differences would be captured in different values of the total factor productivities A and B and of the factor share parameters $\alpha$ and $\eta$. We suppose for now that the shares of $\mathrm{K}$ in the two sectors are the same:

$$
x=\eta
$$

Consequently, all cross-country technology differences arise from differences in the values of A and B.

We have several simplifications of the results obtained in the previous section:

(a) $\boldsymbol{u}=\boldsymbol{v}$, from (11)

(b) $\boldsymbol{Y}=A v K^{\star} H^{1-\otimes}$

(c) $\dot{H}+8 H=B(1-v) K^{\star} H^{1-\propto}$

(d) $\boldsymbol{P}=A / B$, from (14) or (26)

(e) $Q=A K^{\star} H^{1-\otimes}$

$$
\text { (f) } \frac{\boldsymbol{K}}{\boldsymbol{H}}=\frac{\boldsymbol{A}}{\boldsymbol{B}} \frac{\boldsymbol{\alpha}}{1-\boldsymbol{\alpha}} \text {, from (24) and } \mathrm{Z}=1 \text { when } \mathrm{u}=\mathrm{v}
$$

(g) $\gamma=\frac{1}{\theta}\left[\alpha^{\alpha}(1-\alpha)^{1-\alpha} B\left(\frac{A}{B}\right)^{\star s}-\delta-p\right]$

\section{A. One Small Country.}

Consider a small country, denoted 1 , that takes the world price $\mathrm{p}$ as given and that may have

${ }^{5}$ Indeed, in the long run it is not clear that any factor can be fixed (except perhaps land). A Hecksher-Ohlin model seems to make little sense in a growth framework, whereas the Ricardian approach is natural here. 
values of $A_{1}$ and $B_{1}$ different from the world values. (All other parameters equal the world values.)

There are three possible cases: $\mathrm{p}>\mathrm{A}_{1} / \mathrm{B}_{1}, \mathrm{p}=\mathrm{A}_{1} / \mathrm{B}_{1}$, or $\mathrm{p}<\mathrm{A}_{1} / \mathrm{B}_{1}$. Country 1 will find trade

worthwhile whenever $\mathrm{p}$ does not equal $\mathrm{A}_{1} / \mathrm{B}_{1}$. We suppose both $\mathrm{Y}$ and $\mathrm{H}$ trade on the world market.

Let $\mathrm{X}$ denote exports of $\mathrm{Y}$. Then the accumulation constraints for country 1 are

$$
\begin{aligned}
Y & =C+K^{j}+8 K+X \\
& =A_{1} v K^{\star \star} H^{1-\alpha} \\
\dot{H} & +8 H=B_{1}(1-v) K^{\star} H^{1-\star}+\frac{1}{p} X
\end{aligned}
$$

For the closed economy, $\mathrm{X} \equiv 0$ and the values of $\mathrm{K} / \mathrm{H}$ and $\gamma$ are given by (27) and (28); in particular, the growth rate for country 1under autarky is

$$
Y_{1, \Delta u}=\frac{1}{\theta}\left[\alpha^{*}(1-\alpha)^{1-\approx} B_{1}\left(\frac{A_{1}}{B_{1}}\right)^{*}-8-p\right]
$$

When the economy is open, it must choose $\mathrm{X}$ along with everything else. The Hamiltonian for the open economy is

$$
\begin{array}{r}
V=\frac{c^{1-\theta}-1}{1-\theta} e^{-p t}+\phi\left[A_{1}(v K)^{c}(u H)^{1-s}-8 K-C-X\right] \\
+\psi\left\{B_{1}[(1-v) K]^{\eta}[(1-u) H]^{1-\eta}+(1 / p) X-8 H\right\}
\end{array}
$$

and the necessary conditions now include

$$
\dot{\phi}=-\frac{\partial V}{\partial K}=-\phi\left[\ltimes A_{1} v\left(\frac{K}{H}\right)^{\kappa-1}-8\right]-\psi \alpha(1-v) B_{1}\left(\frac{K}{H}\right)^{e-1}
$$




$$
\begin{aligned}
& \dot{\psi}=-\frac{\partial V}{\partial H}=-\phi(1-\alpha) v A_{1}\left(\frac{K}{H}\right)^{c}-\psi\left[(1-\alpha)(1-v) B_{1}\left(\frac{K}{H}\right)^{*}-8\right] \\
& \frac{\partial V}{\partial C}=0=C^{-\theta} e^{-\rho t}-\phi
\end{aligned}
$$

$$
\frac{\partial V}{\partial \nu}=0=\phi A_{1} K^{\star} H^{1-\star}-\psi B_{1} K^{\star} H^{1-\star}
$$

$$
\frac{\partial V}{\partial X}=0=-\phi+\frac{1}{p} \psi
$$

Equation (37) does not depend on any control variable, so we have bang-bang control for $\mathrm{X}$, with $\mathrm{X}$ as high as possible (when $-\phi+(1 / \mathrm{p}) \psi>0$ ) or as low as possible (when $-\phi+(1 / \mathrm{p}) \psi<0)$. An interior solution for $\mathrm{X}$ is possible only in the knife-edge case when $-\phi+(1 / \mathrm{p}) \psi=0$, a condition generally not satisfied as $\phi$ and $\psi$ vary according to their laws of motion (33) and (34).

Country 1 will specialize in one kind of production whenever $X \neq 0$ (i.e., whenever it trades).

To see this result, let us confine attention to cases where trade occurs, that is, where $\mathrm{p} \neq \psi / \phi$.

Suppose the total factor productivity (hereafter, TFP) parameters for the rest of the world are $\mathrm{A}_{2}$ and $\mathrm{B}_{2}$. Then the world economy has

$$
\begin{aligned}
& P_{2}=A_{2} / B_{2} \\
& \frac{K_{2}}{H_{2}}=\frac{A_{2}}{B_{2}} \frac{\alpha}{1-\alpha} \\
& Y_{2}=\frac{1}{\theta}\left[\alpha^{*}(1-\alpha)^{1-\varepsilon} B_{2}\left(\frac{A_{2}}{B_{2}}\right)^{\star}-\delta-p\right]
\end{aligned}
$$

Suppose country 1 has TFP parameters $A_{1}$ and $B_{1}$, not necessarily equal to $A_{2}$ and $B_{2}$. If country 1 is 
closed to trade, then $\psi_{1} / \phi_{1}=\mathrm{p}_{1}=\mathrm{A}_{1} / \mathrm{B}_{1}$. In contrast, when country 1 is open to trade, it has $\mathrm{p}=\mathrm{p}_{2}$ $=A_{2} / B_{2}$, which generally does not equal $A_{1} / B_{1}$. Optimality requires that, for an interior solution, the marginal products of $\mathrm{K}$ used in each sector must be equal, and similarly for the marginal product of $\mathrm{H}$ used in each sector. For K, we would have to have

$$
\frac{\partial Y}{\partial(v K)}=\alpha A_{1}\left(\frac{K}{H}\right)^{\sigma-1}=p \alpha B_{1}\left(\frac{K}{H}\right)^{\alpha-1}=p \frac{\partial(H+\delta H)}{\partial[(1-v) K]}
$$

which is equivalent to

$$
p=\frac{A_{1}}{B_{1}}
$$

Similarly, the condition for $\mathrm{H}$ is

$$
\frac{\partial Y}{\partial(v H)}=(1-\alpha) A_{1}\left(\frac{K}{H}\right)^{\alpha-1}=p(1-\alpha) B_{1}\left(\frac{K}{H}\right)^{\alpha-1}=p \frac{\partial(\dot{H}+\Delta H)}{\partial[(1-v) H]}
$$

which again is equivalent to $p=A_{1} / B_{1}$. However, $p$ is set by world conditions and so equals $A_{2} / B_{2}$, which generally differs from $A_{1} / B_{1}$ for values of $A_{2}$ and $B_{2}$ different from $A_{1}$ and $B_{1}$. If $A_{2} / B_{2}>A_{1}$ $/ \mathrm{B}_{1}$, then

$$
\propto A_{1}\left(\frac{K}{H}\right)^{\alpha-1}<p \propto B_{1}\left(\frac{K}{H}\right)^{\alpha-1} \quad \text { (MPK less for producing } \mathrm{Y} \text { than } \mathrm{H} \text { ) }
$$

and

$$
(1-\propto) A_{1}\left(\frac{K}{H}\right)^{\alpha-1}<p(1-\propto) B_{1}\left(\frac{K}{H}\right)^{\alpha-1} \quad \text { (MPH less for producing } \mathrm{Y} \text { than } \mathrm{H} \text { ) }
$$

so country 1 sets $v=u=0$, produces only $H$, and trades some of it to obtain $Y$. If $A_{2} / B_{2}<A_{1} / B_{1}$, the opposite conclusions hold. Assuming $\mathrm{A}_{2} / \mathrm{B}_{2} \neq \mathrm{A}_{1} / \mathrm{B}_{1}$ thus guarantees both trade and complete 
specialization. We denote the two cases of interest as (a) and (b):

Case (a): $A_{2} / B_{2}=p>A_{1} / B_{1} ; v=u=0$, no production of $Y, X<0$

Case (b): $A_{2} / B_{2}=p<A_{1} / B_{1} ; v=u=1$, no production of $H, X>0$

In either case, country 1 accepts world prices and constrains its choices of $v$ and $u$ to be either 0 or 1 .

It remains to determine the ratio $\mathrm{K} / \mathrm{H}$, which is done by considering the restricted optimization problem appropriate to either Case (a) or Case (b), whichever prevails.

\section{Case (a):}

The Hamiltonian is

$$
V=\frac{C^{1-\theta}-1}{1-\theta} e^{-\rho t}+\phi[-8 K-C-X]+\Psi\left[B_{1} K^{\eta} H^{1-\eta}+(1 / p) X-8 H\right]
$$

The first-order condition for $\mathrm{X}$ is

$$
\begin{aligned}
\frac{\partial V}{\partial X} & =0=-\phi+\frac{1}{p} \psi \\
\rightarrow \frac{\psi}{\phi} & =p=\frac{A_{2}}{B_{2}}
\end{aligned}
$$

The usual necessary conditions give the growth rates for $\phi$ and $\psi$ :

$$
\begin{aligned}
\frac{\dot{\phi}}{\phi} & =8-\frac{\Psi}{\phi} \propto B_{1}\left(\frac{K}{H}\right)^{\alpha-1} \\
& =8-\left(\frac{A_{2}}{B_{2}}\right) \propto B_{1}\left(\frac{K}{H}\right)^{\star-1} \\
\frac{\dot{\Psi}}{\Psi} & =-(1-\alpha) B_{1}\left(\frac{K}{H}\right)^{\alpha}+8
\end{aligned}
$$


Because $\psi / \phi=A_{2} / B_{2}$ is a constant, the growth rates of $\phi$ and $\psi$ must be equal. Equating the two expressions for those growth rates and rearranging terms yields

$$
\begin{aligned}
\frac{K}{H} & =p \frac{\alpha}{1-\alpha} \\
& =\left(\frac{A_{2}}{B_{2}}\right) \frac{\alpha}{1-\alpha}
\end{aligned}
$$

The growth rate $\gamma_{1, \mathrm{a}}$ for $\mathrm{Y}, \mathrm{C}, \mathrm{K}, \mathrm{H}$, and $\mathrm{Q}$ then is

$$
\begin{aligned}
Y_{1, \alpha} & =-\frac{1}{\theta}\left[\frac{\dot{\phi}}{\phi}+\rho\right] \\
& =\frac{1}{\theta}\left[\alpha^{\alpha}(1-\alpha)^{1-\alpha} B_{1}\left(\frac{A_{2}}{B_{2}}\right)^{\alpha}-8-\rho\right]
\end{aligned}
$$

\section{Case (b):}

The Hamiltonian in this case is

$$
V=\frac{C^{1-\theta}-1}{1-\theta} e^{-p t}+\phi\left[A K^{s} H^{1-\varepsilon}-\delta K-X\right]+\psi[(1 / p) X-\delta H]
$$

The type of reasoning as for Case (a) shows that once again

$$
\begin{aligned}
\frac{K}{H} & =p \frac{\alpha}{1-\alpha} \\
& =\left(\frac{A_{2}}{B_{2}}\right) \frac{\alpha}{1-\alpha}
\end{aligned}
$$

and the growth rate $\gamma_{1, \mathrm{~b}}$ is 


$$
\begin{aligned}
Y_{1, b} & =-\frac{1}{\theta}\left[\frac{\dot{\phi}}{\phi}+p\right] \\
& =\frac{1}{\theta}\left[a c(1-a)^{1-\alpha} A_{1}\left(\frac{B_{2}}{A_{2}}\right)^{1-\alpha}-8-p\right]
\end{aligned}
$$

We have four growth rates of interest: the world growth rate $\gamma_{2}$, the country 1 growth rate under autarky $\gamma_{1, \mathrm{Au}}$, the country 1 growth rate with trade in Case (a) $\gamma_{1 \mathrm{a}}$, and the country 1 growth rate with trade in Case (b) $\gamma_{1 b}$. These growth rates are given by equations (40), (31), (42), and (44), which are collected in Table 1 for easy reference. We can see how trade affects growth by examining several pairwise comparisons of the four growth rates.

(I) Autarky versus the world.

The relation between $\gamma_{1, \mathrm{Au}}$ and $\gamma_{2}$ is

$$
Y_{1, A u} \geq Y_{2} \text { as } B_{1}\left(\frac{A_{1}}{B_{1}}\right)^{*} \stackrel{*}{\gtrless} B_{2}\left(\frac{A_{2}}{B_{2}}\right)^{*}
$$

Even if we know which of $A_{1} / B_{1}$ and $A_{2} / B_{2}$ is larger, we still do not know which growth rate is larger. For that, we also must know which of $\mathrm{B}_{1}$ and $\mathrm{B}_{2}$ is larger; that is, we must know which country enjoys an absolute advantage in the production of $\mathrm{H}$. The relevance of absolute advantage here foreshadows a surprisingly important role for absolute advantage in determining the existence of balanced growth, as we shall see soon.

(ii) Autarky versus Case (a).

The relation between the two relevant growth rates is 


$$
\gamma_{1, \Delta u} \gtreqless \gamma_{1, a} \text { as } B_{1}\left(\frac{A_{1}}{B_{1}}\right)^{\alpha} \gtreqless B_{1}\left(\frac{A_{2}}{B_{2}}\right)^{*}
$$

In Case (a), $A_{2} / B_{2}>A_{1} / B_{1}$, so we have

$$
Y_{1, \Delta x}<Y_{1, \alpha}
$$

Trade increases the growth rate.

(iii) Autarky versus Case (b).

The relation between the two growth rates in this case is

$$
\gamma_{1, \Delta u} \gtreqless \gamma_{1, \mathrm{~b}} \text { as } B_{1}\left(\frac{A_{1}}{B_{1}}\right)^{\alpha} \gtreqless A_{1}\left(\frac{B_{2}}{A_{2}}\right)^{1-匹}
$$

Rewrite the left side of the second inequality as

$$
B_{1}\left(\frac{A_{1}}{B_{1}}\right)^{*}=A_{1}^{\star s} B_{1}^{1-\varangle}=A_{1} A_{1}^{s-1} B_{1}^{1-\varangle}=A_{1}\left(\frac{B_{1}}{A_{1}}\right)^{1-\varangle}
$$

and then note that

$$
A_{1}\left(\frac{B_{1}}{A_{1}}\right)^{1-\&}<A_{1}\left(\frac{B_{2}}{A_{2}}\right)^{1-\varepsilon}
$$

because in Case (b) $A_{1} / B_{1}>A_{2} / B_{2}$, which is equivalent to $B_{1} / A_{1}<B_{2} / A_{1}$. Therefore we have

$$
Y_{1, \Delta u}<Y_{1, b}
$$

showing that in this case, too, trade raises the growth rate.

Because trade raises the growth rate in both Case (a) and Case (b), we have the important conclusion that trade unambiguously raises the growth rate of a small country, as long as that country's 
technology differs from the rest of the world's.

\section{B. Two Countries Not Small Relative to Each Other.}

The foregoing analysis adopts the convenient assumption that the small country has no effect on the rest of the world. In mathematical terms, the small country has measure zero. In reality, all countries have positive measure (because there are only finitely many of them and yet the world's measure is positive). Many countries are large enough to be significant contributors to world product. We now examine the effects of trade on the growth rates of two countries large enough to have perceptible effects on each other.

We suppose the world comprises two countries 1 and 2 with fixed populations of equal size. (We examine unequal and growing populations below.) Because the populations are the same size, we can simplify by setting population to one for both countries. As before, the two countries have the same technology except for total factor productivities A and B. Also, $\alpha$ equals $\eta$, so $u=v$. To avoid having to deal with bilateral monopoly arguments, we suppose that each country's economy consists of a large number of competitive firms with identical production functions. Then, even though we are dealing with only two countries facing each other, under the surface are a large number of competitors that guarantee that the competitive solution emerges.

The Hamiltonians for the two countries have the form

$$
\begin{gathered}
V_{i}=\frac{C_{i}^{1-\theta}-1}{1-\theta} e^{-\rho t}+\phi_{i}\left[A_{i} v_{i} K_{i}^{\star *} H_{i}^{1-\star}-C_{i}-X_{i}-8 K_{i}\right] \\
+\Psi_{i}\left[B_{i}\left(1-v_{i}\right) K_{i}^{\star \Delta} H_{i}^{1-\star}+\frac{1}{p} X_{i}-8 H_{i}\right]
\end{gathered}
$$


Under autarky, the two countries separately satisfy the earlier conditions and we have

$$
Y_{i, \Delta u}=\frac{1}{\theta}\left[x^{c}(1-x)^{1-\alpha} B_{i}\left(\frac{A_{i}}{B_{i}}\right)^{\infty}-8-p\right]
$$

With trade, each country satisfies (33) - (37) except that here p is not predetermined but rather is determined endogenously to maintain trade balance. Consequently, $p$ must fall between $A_{1} / B_{1}$ and $A_{2}$ $/ \mathrm{B}_{2}$; otherwise, both countries would try to specialize in and export the same good. Which country has the higher value of $A_{i} / B_{i}$ is arbitrary, so we assume without loss of generality that $A_{1} / B_{1}>A_{2} / B_{2}$. We then have

$$
\frac{A_{1}}{B_{1}} \geq p \geq \frac{A_{2}}{B_{2}}
$$

Country 1 sets $\mathrm{v}=\mathrm{u}=1$, specializes in production of $\mathrm{Y}$, and trades to obtain $\mathrm{H}$. Country 2 does the opposite.

We can find the world equilibrium by analyzing each country separately, taking $\mathrm{p}$ as given, and then imposing the equilibrium condition that $\mathrm{p}$ must be the same for the two countries (equivalently, that $\mathrm{X}_{1}=-\mathrm{X}_{2}$ ). We already have done most of the work, because in the first stage when we treat $\mathrm{p}$ as given, country 1 and country 2 are in the positions of the small country in Case (b) and Case (a), respectively, and satisfy the respective sets of optimality conditions for those two cases. In particular, the growth rates for countries 1 and 2 are

$$
\begin{aligned}
& Y_{1, T}=\frac{1}{\theta}\left[\alpha^{*}(1-\alpha)^{1-\alpha} A_{1}\left(\frac{1}{p}\right)^{1-\alpha}-\delta-p\right] \\
& Y_{2, T}=\frac{1}{\theta}\left[\alpha^{*}(1-\alpha)^{1-\alpha} B_{2} p^{*}-\delta-\rho\right]
\end{aligned}
$$


where the subscript $\mathrm{T}$ indicates that these growth rates pertain when the countries trade.

As before, these growth rates both are greater than the growth rates under autarky for any $p$ between $A_{1} / B_{1}$ and $A_{2} / B_{2}$, where $p$ must lie for trade to occur. We thus have the important conclusion that trade raises the growth rates of both countries (except for an important qualification explained momentarily).

The growth rates in (45) and (46) are not equal for arbitrary p. A necessary and sufficient condition for equality of growth rates is that $\mathrm{p}$ equal the quantity $\mathrm{A}_{1} / \mathrm{B}_{2}$. When $\mathrm{p}$ equals that value, we obtain by substituting into (45) and (46) the common solution

$$
Y=Y_{1, T}=Y_{2, T}=\frac{1}{\theta}\left[a^{\infty}(1-a)^{1-\infty} A_{1}^{\star} B_{2}^{1-\kappa}-\delta-\rho\right]
$$

Otherwise, if $\mathrm{p}>\mathrm{A}_{1} / \mathrm{B}_{2}$, then $\gamma_{1, \mathrm{~T}}<\gamma_{2, \mathrm{~T}}$ and conversely if $\mathrm{p}<\mathrm{A}_{1} / \mathrm{B}_{2}{ }^{6}$ In the present discussion, we are confining attention to balanced growth paths for each of the trading countries. For each country to have balanced growth individually, however, it is necessary that the two countries have the same growth rate, that is, that we have balanced growth for the world. To see this, note that the equations for the growth rates of $\mathrm{K}_{1}$ and $\mathrm{K}_{2}$ become, in the presence of trade and specialization

$$
\begin{aligned}
& \frac{K_{1}}{K_{1}}=A_{1}\left(\frac{K_{1}}{H_{1}}\right)^{-1}-\left(\frac{C_{1}}{K_{1}}\right)-\left(\frac{X_{1}}{K_{1}}\right)-8 \\
& \frac{K_{2}}{K_{2}}=\left(\frac{X_{1}}{K_{2}}\right)-\left(\frac{C_{2}}{K_{2}}\right)-8
\end{aligned}
$$

where we have used the fact that $X_{1}=-X_{2}$ because of trade balance. Balanced growth in each country

${ }^{6}$ Recall that we are maintaining the assumption that $A_{1} / B_{1}>A_{2} / B_{2}$. If we assume the converse, then the foregoing results are reversed. 
requires that these two growth rates for $\mathrm{K}$ be constant. It is straightforward to show that constancy of these growth rates in turn requires that all the ratios on the right sides of the two equations also must be constant. That, however, requires that $\mathrm{K}_{1}$ and $\mathrm{K}_{2}$ both grow at the same rate as $\mathrm{X}_{1}$, which then implies that $\mathrm{K}_{\mathrm{i}}, \mathrm{H}_{\mathrm{i}}, \mathrm{X}_{\mathrm{i}}, \mathrm{C}_{\mathrm{i}}$, and $\mathrm{Y}_{\mathrm{i}}$ all must grow at the same rate as well. Balanced growth for the individual countries and therefore requires that $\mathrm{p}=\mathrm{A}_{1} / \mathrm{B}_{2}$. When that condition is met, countries have the same growth rate, implying that the world has that growth rate, too.

An important issue arises here. Balanced growth requires that $\mathrm{p}$ equals $\mathrm{A}_{1} / \mathrm{B}_{2}$, but, as we have seen above, trade balance requires that $\mathrm{p}$ fall between $\mathrm{A}_{1} / \mathrm{B}_{1}$ and $\mathrm{A}_{2} / \mathrm{B}_{2}$ (otherwise both countries would try to specialize in and export the same good). There is no guarantee, however, that $A_{1} / B_{2}$ falls between $A_{1} / B_{1}$ and $A_{2} / B_{2}$. The only restriction we have imposed so far is that the ratio $A_{1} / B_{1}$ exceed the ratio $A_{2} / B_{2}$ (in order to guarantee that trade occurs). That restriction puts no limits on the ratio $A_{1}$ $/ B_{2}$. If $A_{1} / B_{2}$ falls outside the closed interval $\left[A_{2} / B_{2}, A_{1} / B_{1}\right]$, then $p$ cannot equal it, and balanced growth for the world and for the two countries individually is not possible when the countries trade. Balanced growth thus requires that $A_{1} / B_{2}$ fall inside the interval $\left[A_{2} / B_{2}, A_{1} / B_{1}\right]$.

What conditions on the values of $A_{1}, B_{1}, A_{2}$, and $B_{2}$ are required to guarantee that $A_{1} / B_{2}$ falls inside $\left[A_{2} / B_{2}, A_{1} / B_{1}\right]$ ? Recall that we are assuming for concreteness that $A_{1} / B_{1}>A_{2} / B_{2}$. A little algebra shows that to satisfy this latter condition and also have $A_{1} / B_{2}$ inside the interval $\left[A_{2} / B_{2}, A_{1}\right.$ $\left./ \mathrm{B}_{1}\right]$ requires that

$$
\begin{aligned}
& A_{1}>A_{2} \\
& B_{1}<B_{2}
\end{aligned}
$$

that is, country 1 must have an absolute advantage in producing $\mathrm{Y}$, and country 2 must have an absolute 
advantage in producing $\mathrm{H}^{7}$ When that condition is met, balanced growth is possible. Furthermore, the balanced growth solution is globally asymptotically stable because, from equations (45) and (46), $\mathrm{d} \gamma_{1, \mathrm{~T}} / \mathrm{dp}<0$ and $\mathrm{d} \gamma_{2, \mathrm{~T}} / \mathrm{dp}>0$ for all values of $\mathrm{p}$. At $\mathrm{p}=\mathrm{A}_{1} / \mathrm{B}_{2}$, we have balanced growth, which means $\mathrm{K}$ and $\mathrm{H}$ are growing at the same rate, leaving $\mathrm{p}$ constant. In contrast, if $\mathrm{p}>\mathrm{A}_{1} / \mathrm{B}_{2}$, then $\gamma_{1, \mathrm{~T}}$ falls and $\gamma_{2, \mathrm{~T}}$ rises compared to their balanced growth values. As a result, $\mathrm{K}$ grows more slowly than $\mathrm{H}$, and $\mathrm{p}$ must fall. The same logic shows that $\mathrm{p}$ must rise if it is below $\mathrm{A}_{1} / \mathrm{B}_{2}$. The conclusion is that the balanced growth value of $\mathrm{p}=\mathrm{A}_{1} / \mathrm{B}_{2}$ is globally asymptotically stable. The balanced growth path therefore is a global attractor for the economy whenever it exists.

When (50) is not satisfied, then $A_{1} / B_{2}$ either is greater than $A_{1} / B_{1}$ or is less than $A_{2} / B_{2}$, and no balanced growth rate will exist for either country or for the world. The world price $\mathrm{p}$ will equal whichever of $A_{1} / B_{1}$ or $A_{2} / B_{2}$ is closer to $A_{1} / B_{2}$ (because, as remarked earlier, trade balance requires that $\mathrm{p}$ cannot be outside the interval $\left.\left[\mathrm{A}_{1} / \mathrm{B}_{1}, \mathrm{~A}_{2} / \mathrm{B}_{2}\right]\right)$. The world economy will be at a corner, and the growth rate of one country or the other is unchanged by trade. For example, suppose $A_{1} / B_{2}>A_{1} / B_{1}$, so that $\mathrm{p}=\mathrm{A}_{1} / \mathrm{B}_{1}$. Trade then leaves country 1's growth rate unchanged. Country 2's growth rate does change because $\mathrm{p}=\mathrm{A}_{1} / \mathrm{B}_{1}>\mathrm{A}_{2} / \mathrm{B}_{2}$, but it does not change enough to become equal to country 1's growth rate. This absence of change for one country in the corner solutions is the aforementioned qualification that trade increases the growth rates of the trading partners. For a country in a corner, it need not do so. ${ }^{8}$ Trade therefore does not in itself guarantee balanced growth.

${ }^{7}$ These inequalities are reversed if $A_{1} / B_{1}<A_{2} / B_{2}$.

${ }^{8}$ Recall that we are discussing balanced growth here. Trade always increases the income levels of both trading countries and therefore raises their growth rates temporarily through transition effects, even in the case where one country's growth rate ultimately is left unchanged. 
The intuition for these results is the following. In an interior solution, each country has superior technology in producing one of the goods, each specializes in that good and trades for the other good, and so the growth rate of each country depends on the other country's TFP parameter for the good that the other country is producing. In contrast, a corner solution occurs when one country has an absolute advantage in both goods; consequently, trade does not offer it any technological advantage. Trade still results in a gain for the technologically superior country through the usual comparative advantage argument. To simplify the discussion, suppose $A_{1}>A_{2}, B_{1}>B_{2}$, and $A_{1} / B_{1}>A_{2} / B_{2}$, so that country 1 has the absolute advantage in both goods and country 2 has a comparative advantage in producing the second good, which is $\mathrm{H}$. Country 2 will specialize in producing $\mathrm{H}$ and trade with the country 1 to obtain Y. Total world output will be higher than under autarky, and both countries will have more total output available to them. Country 1, however, does not specialize in producing Y but rather continues to produce both goods. ${ }^{9}$ In effect, country 2 is not "big enough" in a technological sense to fulfill country 1 's demand for $\mathrm{H}$. Because country 1 continues to produce $\mathrm{H}$, it continues to use its own technology, and its growth rate continues to depend only on its own total factor productivities $\mathrm{A}_{1}$ and $\mathrm{B}_{1}$. Country 2 must continue to produce something (in this example, $\mathrm{H}$ ), it must continue to use its inferior technology for that good (that is, $B_{2}$ ). Its growth rate therefore depends on both $A_{1}$ and $B_{2}$. The net result is a partial equalization of technology in the corner case; country 2 abandons $A_{2}$ for $A_{1}$

${ }^{9}$ Formally, this conclusion follows immediately by noting that, because $\mathrm{p}=\mathrm{A}_{1} / \mathrm{B}_{1}$ in the corner solution, trade does not alter the necessary conditions in country 1's optimization problem and so does not alter country 1's production decisions. 
but continues to use the inferior $\mathrm{B}_{2}$ technology to produce $\mathrm{H} .{ }^{10}$

These results have an important implication for the dynamics of the world income distribution. If a corner solution prevails, countries grow at different rates and their incomes diverge. This outcome contrasts with the conclusion obtained by Acemoglu and Ventura (2002) that trade leads to a stable world income distribution. The reason for the difference is that Acemoglu and Ventura restrict their model in such a way that it necessarily yields the equivalent of our interior solution, in which all growth rates are equal. They specify that each country is endowed with a monopoly in the production of a subset of intermediate goods, which no other country ever is permitted to produce. Given this exogenous fixed pattern of specialization, trade improves and equalizes all countries' growth rates by allowing each country to use all intermediate goods that it cannot produce itself. The resulting equilibrium is mathematically equivalent to the interior solution of the model developed here. In the less constrained analysis of the present model, however, the pattern of production is determined endogenously, and corner solutions are possible outcomes. In the corners, balanced growth does not occur, and the world income distribution is not stable.

The results of this section also make clear why the "small" country in our earlier discussion experienced an increase in its growth rate but did not move all the way to the world's growth rate. The small country is infinitesimal, and the large rest of the world takes no notice of its existence.

Consequently, the rest of the world does not adopt any of the small country's technology (i.e., the rest

\footnotetext{
${ }^{10}$ Asymptotically, of course, balanced growth emerges because the disadvantaged country's lower growth rate means that its share of world output vanishes in the limit, leaving the world growth rate equal to that of the advantaged country.
} 
of the world behaves as if it is in a corner), whereas the small country does effectively adopt some of the rest of the world's technology by abandoning production in one good and letting the rest of the world produce it. The small country thus acts like the absolutely disadvantaged country in the foregoing discussion of corner solutions.

Comparative advantage matters for growth; it determines which good will be produced and traded by each country, and it leads to increased growth for at least some countries through trade. However, absolute advantage matters, too; the pattern of absolute advantages determines whether balanced growth is possible for either individual countries or the world as a whole and whether a particular country will experience a higher growth rate as a result of trade. This importance of absolute advantage is unusual for trade theory.

\section{A Pure Consumption Good.}

So far, all considered have been factors of production. We can derive some results for goods that are not factors of production by considering a special case of the foregoing model in which $\alpha$ equals zero. In that case, $\mathrm{K}$ is no longer useful, and all output in the $\mathrm{Y}$ sector is devoted to consumption $\mathrm{C}$. The autarkic growth rate for country $i$ becomes

$$
\gamma_{i, \Delta e}=\frac{1}{\theta}\left[B_{i}-8-p\right]
$$

Because the output of the $\mathrm{Y}$ sector no longer is used as a factor of production, the TFP parameter $\mathrm{A}_{\mathrm{i}}$ from that sector no longer affects the growth rate. With trade, the growth rate for the interior solution is simply

$$
Y=Y_{1, I}=Y_{2, I}=\frac{1}{\theta}\left[B_{2}-8-\rho\right]
$$


The growth rate of both countries is determined only by TFP in the $\mathrm{H}$ sector of country 2, which is the country that specializes in producing $H$ because of our assumption that $A_{1} / B_{1}>A_{2} / B_{2}$. Country 1 's TFP parameter $\mathrm{A}_{1}$ plays no role in the growth rate because now $\mathrm{Y}$ is not useful as a factor of production.

As before, an interior solution requires that (50) be satisfied; otherwise the world price $p$ will be at one of the boundary values $A_{1} / B_{1}$ or $A_{2} / B_{2}$. When $p$ equals $A_{2} / B_{2}$, country 2 has an absolute advantage in both goods. Country 1 produces only $\mathrm{Y}$ and imports $\mathrm{H}$, and country 2 produces both $\mathrm{Y}$ and $\mathrm{H}$ and imports $\mathrm{Y}$. The growth rates for the two countries are obtained from (45) and (46) by substituting $\mathrm{A}_{2} / \mathrm{B}_{2}$ for $p$ and noting that $\alpha=0$ :

$$
\gamma_{1, T}=\frac{1}{\theta}\left[A_{1}\left(\frac{B_{2}}{A_{2}}\right)-8-\rho\right]
$$

$$
Y_{2, T}=\frac{1}{\theta}\left[B_{2}-8-\rho\right]
$$

As before, a little algebra shows that country 1's growth rate $\gamma_{1 \mathrm{~T}}$ is larger than under autarky but smaller than country 2 's growth rate $\gamma_{2 \mathrm{~T}}$. Thus, as when $\alpha$ is not zero, trade has no effect on the growth rate of the absolutely advantaged country, raises the growth rate of the absolutely disadvantaged country, but leaves the disadvantaged country's growth rate below that of the advantaged country. Results are slightly different at the other corner. When $p$ equals $A_{1} / B_{1}$, country 1 produces both $\mathrm{Y}$ and $\mathrm{H}$ and imports $\mathrm{H}$, and country 2 produces only $\mathrm{H}$ and imports $\mathrm{Y}$. The growth rates for the two countries are:

$$
Y_{1, T}=\frac{1}{\theta}\left[B_{1}-8-p\right]
$$




$$
Y_{2, I}=\frac{1}{\theta}\left[B_{2}-\delta-\rho\right]
$$

which are the same as under autarky. ${ }^{11}$ In this case, trade does not change either country's growth rate.

\section{An Important Implication for Economic Development.}

This last pair of corner results makes clear a strong policy implication for economic

development that emerges from our analysis: what is important for economic growth is not the good that is exported but rather the good that is imported. Growth rates depend on TFP in sectors that produce factors of production. Trade can raise a country's growth rate by allowing that country to substitute another country's higher TFP for its own. It is the importation of capital that can raise a country's growth rate; it does not matter what good is exported to pay for that capital. It therefore may be very good policy for underdeveloped countries to export consumption goods and natural resources in exchange for capital (human as well as physical); likewise, it may be very bad policy for those countries to try to create their own industries for producing capital. In particular, a country that has an absolute disadvantage in everything but a comparative advantage in consumption goods can increase its growth rate by concentrating on producing consumption goods and exporting them in exchange for capital. More problematic would be the optimal policy for a country with universal absolute disadvantage but comparative advantage in some type of capital. ${ }^{12}$ Such a country cannot raise its growth rate by

\footnotetext{
${ }^{11}$ In this case, the mathematical constraints placed on the problem (i.e., $A_{1} / B_{2} \geq A_{1} / B_{1}=p>$ $A_{2} / B_{2}$ ) imply that $B_{1} \geq B_{2}$, so that $\gamma_{1 \mathrm{~T}} \geq \gamma_{2 T}$.

${ }^{12}$ This case may be no more than an intellectual curiosity. It seems more likely that a country with absolute disadvantage in everything will have a comparative advantage in natural resources or certain consumption goods, such as fruit, than in the production of any type of capital. Capital production, by its nature, seems to be the province of technologically advanced countries.
} 
exporting capital.

These results suggest a possible reason why some countries' growth rates are persistently below others'. Any country that is absolutely disadvantaged at everything has nothing to offer the world technologically. It will, of course, have comparative advantage in something, and it should produce and export that good. If it obtains a factor of production in return, then its growth rate will be increased by trade. Nonetheless, the growth rate will remain below that of the technological leaders. The country must move to a position of absolute advantage in something to obtain a growth rate equal to that of most advanced countries. It is interesting that it only needs an absolute advantage in producing one good to attain the highest possible growth rate; that is sufficient to result in effective technology equalization with other advanced countries.

An apparent implication is that a country should drop all barriers to trade if it is to be on its growth rate frontier, but things may not be so straightforward. A country with no absolute advantage cannot attain the highest growth rates prevailing in the rest of the world. To do so, it must raise its absolute advantage in something. Optimal policy may be to protect a domestic industry and perhaps also subsidize it until domestic firms have developed sufficient technical knowledge to achieve absolute advantage in the world. Such a policy will impose short-run costs through inefficient trade barriers and through taxation to finance the subsidy, but if the policy raises the growth rate, then eventually output will be higher than it would have been in the absence of the policy. This is the old infant industry argument in a slightly different garb. Whether the benefits of such a policy outweigh the costs requires an beyond the scope of the present study. An important aspect of any such policy, however, is that it must favor goods that can be exchanged for factors of production on the world market if it is to 
increase the economy's growth rate.

The feasibility of eliminating an absolute disadvantage probably depends on the reason the disadvantage exists. Exogenously low TFP in a particular industry, perhaps because a country lacks appropriate climate, is unlikely to be amenable to cost-effective change, but endogenously low TFP is another matter. Industry composition affects TFP (Chanda and Dalgaard, 2002), so policy that encourages structural change may be able to raise TFP and thus create an absolute advantage. ${ }^{13}$ Some kinds of choices also can confer absolute disadvantage. Under dynastic management, for example, owners of firms bequeath management control on their heirs rather than search the market for the best managerial talent. Dynastic management is the predominant pattern of firm management in underdeveloped countries, and there may be good reasons for choosing it (such as solving a principalagent problem). Whatever the reason for its existence, Caselli and Gennaioli (2002) show that dynastic management tends to create persistent differences in total factor productivity, thus causing persistent absolute disadvantage. Government policies that discourage such practices could raise TFP and eliminate the disadvantage.

\section{Generalizations}

We can relax some of the restrictions used in the foregoing analysis to obtain more general results.

${ }^{13}$ Chanda and Dalgaard's discussion concerns TFP at the national level, but the same argument apparently applies at the industry level. 


\section{A. Unequal Populations and Population Growth.}

Suppose countries 1 and 2 have populations $\mathrm{N}_{1}$ and $\mathrm{N}_{2}$ growing at rates $\mathrm{n}_{1}$ and $\mathrm{n}_{2}$. Introducing population growth raises the issue of whether to weight utility by population size in the objective function. In the Cass growth model, this choice has a minor effect on the nature of the steady state but does not affect the general behavior of the economy. The choice has a more important and rather puzzling effect here. We can write the general function

$$
\int_{0}^{e} \frac{e_{t}^{1-\theta}-1}{1-\theta} e^{-p t} N_{t}^{2} d t
$$

where $c_{i}=C_{i} / N_{i}$ and $\epsilon$ is 1 if we weight by population and is 0 otherwise. The Hamiltonian is

$$
\begin{aligned}
& V_{i}=\frac{c_{i}^{1-\theta}-1}{1-\theta} e^{-\rho t} N_{i}^{\varepsilon}+\phi_{i}\left[A_{i} v_{i} K_{i}^{*} H_{i}^{1-\theta}-N_{i} c_{i}-X_{i}-8 K_{i}\right] \\
& +\Psi_{i}\left[B_{i}\left(1-v_{i}\right) K_{i}^{\infty} H_{i}^{1-\infty}+\frac{1}{p} X_{i}-8 H_{i}\right]
\end{aligned}
$$

The only necessary condition affected by population is the first-order condition for consumption:

$$
\begin{aligned}
\frac{\partial V}{\partial c} & =0=c_{i}^{-\theta} e^{-p t} N_{i}^{E}-\phi_{i} N_{i} \\
& \rightarrow-\theta \frac{\dot{c} c_{i}}{c_{i}}-p+\epsilon n_{i}=\frac{\dot{\phi}_{i}}{\phi_{i}}+n_{i} \\
& \rightarrow \gamma=\frac{\dot{c}_{t}}{c_{i}}=-\frac{1}{\theta}\left[\frac{\dot{\phi}_{i}}{\phi_{i}}+p+(1-\epsilon) n_{i}\right]
\end{aligned}
$$

where $\gamma$ now is growth of income per person. (Absolute growth is trivially $\gamma^{\mathrm{ABS}}=\gamma+\mathrm{n}_{\mathrm{i}}$.)

All the previous analysis holds up to the point of determining $\mathrm{p}$. If we assume $\mathrm{A}_{1}>\mathrm{A}_{2}$ and $\mathrm{B}_{1}<$ 
$\mathrm{B}_{2}$ as before, then country 1 produces $\mathrm{Y}$ and country 2 produces $\mathrm{H}$. The two countries' growth rates are

$$
\begin{aligned}
& Y_{1}=\frac{1}{\theta}\left[\alpha^{\alpha}(1-\alpha)^{1-\alpha} A_{1} p^{\alpha-1}-\delta-p-(1-\varepsilon) n_{1}\right] \\
& Y_{2}=\frac{1}{\theta}\left[\alpha^{\alpha}(1-\alpha)^{1-\alpha} B_{2} p^{\alpha-1}-\delta-p-(1-\varepsilon) n_{2}\right]
\end{aligned}
$$

Balanced growth requires $\gamma_{1}=\gamma_{2}$ :

$$
\Rightarrow \alpha^{\star}(1-\kappa)^{1-\alpha} A_{1} p^{\alpha-1}-(1-\varepsilon) n_{1}=\alpha^{\star}(1-\alpha)^{1-\alpha} B_{2} p^{\alpha-1}-(1-\varepsilon) m_{2}
$$

If either (i) $\mathrm{n}_{1}=\mathrm{n}_{2}$ or (ii) $\epsilon=1$, then (53) reduces to what we had earlier, yielding the same results.

However, if both $\mathrm{n}_{1} \neq \mathrm{n}_{2}$ and $\epsilon=0$, then no analytical solution for $\mathrm{p}$ is possible. This strong effect of the choice of $\epsilon$ is surprising and puzzling.

Notice that the population sizes $\mathrm{N}_{1}$ and $\mathrm{N}_{2}$ are absent from the solution, showing the irrelevance of the physical sizes of the economies and also emphasizing the absence of scale effects.

\section{B. Inequality Between $\alpha$ and $\eta$.}

When the share parameters $\alpha$ and $\eta$ differ from each other, derivations are considerably messier, but the final results are clear generalizations of what we have obtained so far. For example, in the case of two countries that are not small, the growth rate under autarky is

$\gamma_{i, \Delta u}=\frac{1}{\theta}\left[\alpha^{\frac{\Delta \eta}{1-\alpha+\eta}}(1-\alpha)^{\frac{(1-\alpha) \eta}{1-\alpha+\eta}} \eta^{\frac{(1-\varepsilon) \eta}{1-\alpha+\eta}}(1-\eta)^{\frac{(1-\varepsilon)(1-\eta)}{1-\alpha+\eta}} A_{i}^{\frac{\eta}{1-\alpha+\eta}} B_{i}^{\frac{1-\alpha}{1-\alpha+\eta}}-\delta-p\right]$

Notice in particular that $A_{i}$ and $B_{i}$ are exponentially weighted as before, just with more complicated exponents. The growth rate under trade that is consistent with balanced growth is 


$$
\gamma=\frac{1}{\theta}\left[\alpha^{\frac{s \eta}{1-s+\eta}}(1-\alpha)^{\frac{(1-s) \eta}{1-s+\eta}} \eta^{\frac{(1-s) \eta}{1-s+\eta}}(1-\eta)^{\frac{(1-s)(1-\eta)}{1-s+\eta}} A_{1}^{\frac{\eta}{1-s+\eta}} B_{3}^{\frac{1-s}{1-s+\eta}}-\delta-p\right]
$$

which is greater than $\gamma_{\mathrm{i}, \mathrm{Au}}$. Thus we get qualitatively the same results as in the simpler case where $\alpha=$

$\eta$.

\section{The Equalization Theorem}

The main results we have obtained can be summarized in the following theorem.

Technology Equalization Theorem. Suppose the following:

(I) the world comprises two countries, denoted 1 and 2, each having the same constant relative risk aversion utility function

(ii) two goods are produced in separate sectors with Cobb-Douglas production functions

(iii) total factor productivities differ across the two countries for each sector.

Then:

(I) If each country has an absolute advantage in producing one of the goods, a balanced growth rate exists, is common to all countries and therefore to the world as a whole, and is globally asymptotically stable. The balanced growth rate with trade is higher than either country's autarkic growth rate and is the same as the growth rate that would emerge under technology transfer.

(II) If one country has an absolute advantage in producing both goods, then a balanced growth rate does not exist for any country or for the world. The growth rate for the country with the absolute advantages is the same as its autarkic growth rate. The growth rate for the other country depends on what kind of good is imported. If a factor of production is imported, the growth rate with trade is more than the autarkic growth rate but less than the growth rate for the country with the absolute advantages. If a consumption good is imported, the growth rate is the same as the autarkic growth rate.

\section{Conclusion}

We have seen that trade in goods can raise the growth rates of all trading partners through a 
combination of comparative advantage and absolute advantage, without there being any scale effects, technology transfer, research and development, or international investment. Comparative advantage determines the pattern of trade; absolute advantage determines whether a balanced growth rate exists. If every country has an absolute advantage in at least one good, then a balanced growth path for the world exists and is globally asymptotically stable. Along this balanced growth path, each country's growth rate is the same as if it had exchanged technology with other countries; trade leads to a growth outcome that is equivalent to that which would have emerged from technology transfer. If any country has no absolute in any good, then no balanced growth path for the world is feasible. The technologically backward countries' growth rates generally are increased by trade, as if there were a partial technology transfer, but the resulting growth rate remains lower than that of technologically advanced countries. We thus have the two major implications that trade generally increases growth rates and that trade leads to growth outcomes that are equivalent to what would emerge from technology transfer. The analysis suggests that a possible reason why some countries' growth rates persistently lag behind others' is that those countries have an absolute disadvantage in producing everything. It therefore also suggests that those same countries may be able to improve their growth rates if they can design government policies that lead to greater TFP in some industry and thus create an absolute advantage. However, it is important in such a case to create the advantage in a good that can be exchanged for factors of production in the world market because trade raises the growth rate only when it results in importation of factors of production. 


\section{Table 1}

Growth Rates for One Small Country

World:

$y_{W}=\frac{1}{\theta}\left[\alpha^{*}(1-x)^{1-\epsilon} B_{W}\left(\frac{A_{W}}{B_{W}}\right)^{c}-8-\rho\right]$

Country S, Autarky:

$$
\gamma_{\delta, \Delta u}=\frac{1}{\theta}\left[\alpha^{\star}(1-\alpha)^{1-\infty} B_{S}\left(\frac{A_{\delta}}{B_{S}}\right)^{\star}-8-p\right]
$$

Country S, Trade, Case (a):

$$
Y_{\delta, \alpha}=\frac{1}{\theta}\left[\alpha^{*}(1-\alpha)^{1-\kappa} B_{\delta}\left(\frac{A_{W}}{B_{W}}\right)^{\alpha}-\delta-p\right]
$$

Country S, Trade, Case (b):

$$
Y_{\Sigma, b}=\frac{1}{\theta}\left[\alpha^{\star}(1-\alpha)^{1-\star} A_{S}\left(\frac{B_{W}}{A_{W}}\right)^{1-\alpha}-\delta-p\right]
$$




\section{References}

Acemoglu, Daron, and Jaume Ventura, “The World Distribution of Income,” Quarterly Journal of Economics 2002.

Alcala, Francisco, and Antonio Ciccone, “Trade and Productivity,” CEPR working paper DP3095, December 2001.

Backus, David, Patrick Kehoe, and Timothy Kehoe, "In Search of Scale Effects in Trade and Growth," Journal of Economic Theory 58, December 1992, pp. 377-409.

Barro, Robert J., and Xavier Sala-I-Martin, Economic Growth, McGraw-Hill, New York, 1995.

Barro, Robert J., and Xavier Sala-I-Martin, “Technological Diffusion, Convergence, and Growth,” Journal of Economic Growth 2, March 1997, pp. 1-26.

Caselli, Francesco, and Nicola Gennaioli, “Dynastic Management,” Harvard University working paper, April 2002.

Chanda, Areendam, and Carl-Johan Dalgaard, "Dual Economies and International TFP Differences,” working paper, November 2002, North Carolina State University and University of Copenhagen.

Connolly, Michelle, "North-South Technological Diffusion: A New Case for Dynamic Gains from Trade," Duke University Economics Department working paper \#99-08, 2000.

Frankel, Jeffrey A., and David Romer, "Does Trade Cause Growth?” American Economic Review 89, June 1999, pp. 379-399.

Grossman, Gene, and Elnahan Helpman, “Comparative Advantage and Long-Run Growth,” American Economic Review 80, September 1990, pp. 796-815

Grossman, Gene, and Elnahan Helpman, Innovation and Growth in the Global Economy, MIT Press, Cambridge, 1991.

Grossman, Gene, and Elnahan Helpman, "International R\&D Spillovers,” European Economic Review 39, May 1995, pp. 859-887.

Howitt, Peter, "Endogenous Growth and Cross-Country Income Differences," American Economic Review 90, September 2000, pp. 829-846.

Kremer, Michael, “Population Growth and Technical Change: One Million B.C. to 1990," Quarterly Journal of Economics 108, August 1993, pp. 681-716.

Rivera-Batiz and Romer, "Economic Integration and Endogenous Growth,” Quarterly Journal of Economics 106, May 1991, pp. 531-555.

Young, Alwyn, "Learning By Doing and the Dynamic Effects of International Trade," Quarterly Journal of Economics 106, May 1991, pp. 369-405.

Ventura, Jaume, “Growth and Interdependence,” Quarterly Journal of Economics 112, February 1997, pp. 57-84. 